\title{
SHIFT SCHEDULE, WORK-FAMILY RELATIONSHIPS, MARITAL COMMUNICATION, JOB SATISFACTION AND HEALTH AMONG TRANSPORT SERVICE SHIFT WORKERS
}

\section{IRENA ISKRA-GOLEC ${ }^{1}$, LAWRENCE SMITH², EWA WILCZEK-RUŻYCZKA ${ }^{3}$, PATRYCJA SIEMIGINOWSKA ${ }^{4}$, and JOANNA WĄTROBA ${ }^{4}$}

${ }^{1}$ University of Social Sciences and Humanities, Poznań, Poland

Institute of Psychology

${ }^{2}$ University of Leeds, Leeds, UK

Department of Psychology

${ }^{3}$ Andrzej Frycz Modrzewski Cracow University, Kraków, Poland

Faculty of Psychology and Humanities

${ }^{4}$ Jagiellonian University, Kraków, Poland

Institute of Applied Psychology

\begin{abstract}
Objectives: Existing research has documented that shiftwork consequences may depend on the shift system parameters. Fast rotating systems (1-3 shifts of the same kind in a row) and day work have been found to be less disruptive biologically and socially than slower rotating systems and afternoon and night work. The aim of this study was to compare day workers and shift workers of different systems in terms of rotation speed and shifts worked with regard to work-family and family-work positive and negative spillover, marital communication style, job satisfaction and health. Material and Methods: Employees $(\mathrm{N}=168)$ of the maintenance workshops of transportation service working different shift systems (day shift, weekly rotating 2 and 3-shift system, and fast rotating 3-shift system) participated in the study. They completed the WorkFamily Spillover Questionnaire, Marital Communication Questionnaire, Minnesota Job Satisfaction Questionnaire and the Physical Health Questionnaire (a part of the Standard Shiftwork Index). Results: The workers of quicker rotating 3-shift systems reported significantly higher scores of family-to-work facilitation $(F(3,165)=4.175, p=0.007)$ and a higher level of constructive style of marital communication (Engagement $\mathrm{F}(3,165)=2.761, \mathrm{p}=0.044$ ) than the workers of slower rotating 2-shift systems. There were no differences between the groups of workers with regard to health and job satisfaction. Conclusions: A higher level of work-family facilitation and a more constructive style of marital communication were found among the workers of faster rotating 3-shift system when compared to the workers of a slower rotating 2-shift system (afternoon, night). This may indicate that the fast rotating shift system in contrary to the slower rotating one is more friendly for the work and family domains and for the relationship between them. Int J Occup Med Environ Health 2017;30(1):121-131
\end{abstract}

Key words:

Health, Job satisfaction, Shift work, Marital communication, Work-family relation, Transport service workers

Funding: the research was financed by the state budget received by the Jagiellonian University and was a part of a project "Work-family relation and stress, burnout, job satisfaction and satisfaction with life among shift workers in different shift systems" (K/ZDS/002011). Project manager: Irena Iskra-Golec, Ph.D.

Received: April 25, 2015. Accepted: January 11, 2016.

Corresponding author: I. Iskra-Golec, University of Social Sciences and Humanities, Institute of Psychology, Kutrzeby 10, 60-995 Poznań, Poland (e-mail: upiskra@cyf-kr.edu.pl). 


\section{INTRODUCTION}

\section{Shift work and positive and negative relationship between work and family}

There is a scarcity of studies on work-family relationships in shift workers despite a significant proportion of people, i.e., $17 \%$ of those employed in Europe [1] and $17.7 \%$ in the USA [2] working outside traditional weekday hours (5 days/week, 7 a.m. -6 p.m.). Shift work including night work has potential to exert both negative and positive effects on non-work life just because of its non-standard working time arrangements. Shift work schedules may cause work-family conflict understood as "a form of inter-role conflict, in which the role pressures from work and family domains are mutually incompatible in some respect" [3].

Shift work schedules may cause at least 2 forms of such a conflict, i.e., strain-based conflict and time-based conflict. Shift work, including night work, has been reported to disturb biological rhythms and social routines, which results in sleep problems and impaired health [4,5]. These, in turn, may lead to strain-based conflict that appears when exposure to stress in one domain leads to strain that affects ability to perform in the other domain [3]. Shift workers while working afternoon and night shift experience a reverse timing of activity and rest patern to that of their families. This limits the amount of time spent together, which may result in time-based conflict, which occurs when time spent on tasks of one role inhibits completion of responsibilities in another role [3].

Thus, significantly greater work-family conflict has been found in military police personnel working non-day or weekend shifts compared to their day working counterparts [6], and among women working shifts when compared to women working standard hours [7,8].

The number of weekly work hours and frequent Sunday work were associated with higher levels of work-family conflict in health care professionals [9]. Rotating shift systems were associated with negative spillover in shift workers with families [10]. Night work and rotating shifts were associated with work-family conflict among parents, especially $[11,12]$ in parents having children under the age of $13[13,14]$.

There are inconsistent findings with regard to the research on shift schedule and marital outcomes like marital quality (marital happiness and marital conflict) [15], marital satisfaction [16], and style of communication. Studies among women [17] and couples [13] have shown lower marital quality in late shifts and rotating shifts workers. However, other research has not shown negative effects of shift work and late shifts on marital quality [18]. Style of communication in shift working couples has not been extensively studied yet.

Studies from work-family relationship area have indicated that the style of communication (constructive vs. destructive) between partners mediated the relationship between work-family conflict and marital satisfaction [16]. Properly designed shift schedules may limit negative effects of shift work or even may exert positive effects allowing, for example, for free time during week days, which may facilitate rest and fulfillment of the family and homecare duties. Recently, research has increasingly concentrated on benefits resulting from performing multiple roles developing such concepts like work-family positive spillover, facilitation, enhancement, enrichment [19]. The distinction between these concepts is not clear but some authors [20] try to differentiate between them. Work-family facilitation is a form of synergy in which resources gained in one role make it easier to perform the other role [21]. Indeed, there are studies showing lack of negative effects of shift work as well as positive aspects of working shifts on work-family relation [18]. Other studies have reported that shift work may facilitate child care if parents' work times are complementary [22], minimize costs of child care [23] and may help involve fathers in child care [18]. Nevertheless, there is a shortage of studies on the positive linkages between shift work and family, which is consistent 
with the more general neglect of the possible benefits of participating in multiple roles in work-family research.

\section{Shift system parameters and shift work-family effects}

Shift work effects on workers' well-being depend largely on shift system parameters [5,24]. There are relatively few studies considering effects of shift schedule parameters on work-family relationship. More pronounced work-family conflict has been linked to rotating shift systems compared to fixed shift systems [10], to backward-rotating compared to forward-rotating schedules [11] and to shift systems with an irregular rotation compared to a regular rotation [10]. Working late shifts has been associated with reduced marital quality among men, while rotating schedules have been reported to create difficulties in performing family roles for women [18,25]. Mills and Täht [18] have found that only non-standard schedules with varying hours had a negative effect on relationship quality among women but, conversely, a positive effect for shift working men with young children at home. No effect of shift length ( 8 h vs. $12 \mathrm{~h}$ regarded as more family friendly) on work-family conflict and health has been reported by Loudoun [26]. Control over the shift work schedule was found to moderate its negative impact on family life [27].

The aim of this study was to examine the differences between day workers and shift workers on systems differing with regard to rotation speed and the shifts worked in relation to work-family and family-work positive and negative spillover, job satisfaction, marital communication style and health.

According to the shift work-stress theoretical models [28], shift work health and social effects depend among others on shift system parameters, like: speed of rotation, regularity, and a number of consecutive days off. Research has shown that regular fast rotating shift systems (alternating sequences of 1-3 shifts of the same kind in a row) are regarded as biologically and socially less disruptive than those featuring longer rotation $[24,29]$.
A regular fast rotation might be less disruptive for biological rhythms because it may not involve more intensive circadian partial phase adjustment to an altered sleep/ wake pattern during night shifts and subsequent re-adjustment while on day shift. That, in turn, may result in better health and well-being. Thus, day workers and workers on a 4 team 3-shift system (morning, afternoon, and night shifts) experience: a) fewer health complaints, b) greater job satisfaction compared to workers on slower (weekly) rotating 3-shift, and 2-shift systems (afternoon and night shifts only) (hypothesis 1).

The speed of rotation and allocation of time for work and rest are key characteristics of work schedules affecting family life. Working on afternoon shifts and during weekends has been found to be detrimental to family life since these times are the most popular times for social and family life in the day oriented society $[24,29]$. Therefore, fast rotating systems and day work might be less disruptive for family life by minimizing the times of workers' absences from home during the most socially attractive times (afternoons and weekends). Thus, work-family conflict might be less severe in fast rotating shift systems and day work when compared to those of longer rotations with afternoon and night work.

In this study it is assumed that workers on a 4 team 3-shift system (morning, afternoon, and night shifts) and day workers experience: a) greater work-family and family-work facilitation and b) lower work-family and family-work conflict compared to workers on weekly rotating 3-shift, and 2-shift systems (afternoon and night shifts only) (hypothesis 2).

There is no direct evidence on the effect of a shift system on the marital communication style. However, there is a body of evidence showing that less socially valuable time spent with family, like working long spans of afternoon or evening shifts, may lead to worsening performance on family roles and to other negative family outcomes [29]. 
Limitation of time spent together with a spouse may make it more difficult to develop and maintain a constructive marital communication style. Thus, day workers and workers on a 4 team 3 -shift system (morning, afternoon, and night shifts) experience more constructive (engaged) style of marital communication compared to workers on slower (weekly) rotating 3-shift, and 2-shift systems (afternoon and night shifts only) (hypothesis 3). This, in turn, may increase positive relations between work and family. Family resources have been found to be positively related to facilitation between work and family [30].

\section{MATERIAL AND METHODS}

\section{Procedure and participants}

The research involved a convenience sample of workers employed in bus and tram transport service maintenance workshops in a large Polish town. Self-reported questionnaires were distributed to the participants. Of 250 participants who completed the questionnaires, 7 were excluded because of missing data. Another 75 participants were excluded because they did not meet the inclusion criteria (i.e., being married and having at least 1 child). Thus, the final sample included 168 male blue collar day and shift workers. Majority of them (81\%) had low attainment of educational level (primary or trade school).
They were middle aged, had a relatively long work experience and their youngest children were adolescent (Table 1). They worked 4 types of 8-h shift schedules; a fixed day shift $(\mathrm{N}=31)$, and 3 different types of regular forward rotation shift systems; a weekly rotating 2-shift (afternoon and night) schedule ( $\mathrm{N}=35)$, a weekly rotating 3-shift (morning, afternoon, night) schedule $(\mathrm{N}=38)$ with $48 \mathrm{~h}$ off (weekend) after each 5 days shift blocks, and a 4 team 3 -shift system with 4 days on each shift $(\mathrm{N}=64)$ and $24 \mathrm{~h}$ off after blocks of morning and afternoon shifts, and $48 \mathrm{~h}$ off after a block of night shifts. All the shift systems had the same timing of shifts (morning: 6 a.m. -2 p.m., afternoon: 2 p.m. -10 p.m., and night: 10 p.m. -6 a.m.).

\section{Measures}

\section{Work-family relation}

The Work-Family Spillover Scale was used to measure work-family and family-work positive (facilitation) and negative spillover (conflict) [31,32]. The scale comprised 16 items with 4 questions for each direction (family-to-work and work-to-family) and for each valence (conflict and facilitation) of the work-family relationship. Items belonging to the conflict scales concerned the extent to which time pressures and strain in one role interfered with performance in the other role. A sample item for

Table 1. Characteristics of the study group - the workers employed in bus and tram transport service maintenance workshops in a large Polish town

\begin{tabular}{|c|c|c|c|c|}
\hline \multirow[t]{2}{*}{ Work system } & \multicolumn{4}{|c|}{$\begin{array}{c}\text { Respondents } \\
(\mathrm{N}=168) \\
(\mathrm{M} \pm \mathrm{SD})\end{array}$} \\
\hline & $\begin{array}{c}\text { age } \\
\text { [years] }\end{array}$ & $\begin{array}{l}\text { work experience } \\
\text { [years] }\end{array}$ & $\begin{array}{c}\text { children } \\
{[\mathrm{n}]}\end{array}$ & $\begin{array}{l}\text { the youngest child age } \\
\text { [years] }\end{array}$ \\
\hline Day shifts $(\mathrm{N}=31)$ & $46.57 \pm 6.77$ & $29.22 \pm 7.39$ & $2.04 \pm 0.82$ & $13.25 \pm 6.03$ \\
\hline Weekly rotating 2-shift $(\mathrm{N}=38)$ & $46.93 \pm 7.68$ & $30.12 \pm 6.82$ & $2.05 \pm 0.97$ & $15.57 \pm 7.41$ \\
\hline Weekly rotating 3-shift $(\mathrm{N}=35)$ & $46.61 \pm 7.62$ & $29.74 \pm 7.31$ & $1.89 \pm 0.91$ & $16.29 \pm 8.87$ \\
\hline 4 team 3-shift $(\mathrm{N}=64)$ & $47.03 \pm 6.27$ & $30.59 \pm 6.60$ & $1.95 \pm 0.78$ & $16.71 \pm 9.39$ \\
\hline
\end{tabular}

$\mathrm{N}$ - respondents.

M - mean; SD - standard deviation. 
work-family conflict was: "Your job reduces the effort you can give to activities at home" and for family-work conflict it was: "Responsibilities at home reduce the effort you can devote to your job."

The items belonging to the Scale of Work-Family Facilitation concerned the extent to which skills, behaviors and positive mood from work positively influenced one's performance in the family domain. A sample item of this scale was: "The things you do at work help you deal with personal and practical issues at home." Items belonging to the Scale of Family-Work Facilitation assessed the extent to which the positive mood, behaviors, and sense of accomplishment, support or resources received in the family domain positively affected performance on work roles. An example item for this scale was: "Talking with someone at home helps you deal with the problems at work." The participants were asked to indicate how often they experienced each work-family situation during the last year using a 5-point frequency scale $(1=$ all the time, $5=$ never $)$. Higher scores reflected bigger extent of a given work-tofamily or family-to-work spillover.

The forward-back translation of the scale was done for the purpose of the studies carried out in the Institute of Applied Psychology. The scale was independently translated into Polish by 3 psychologists, experts in English and workfamily problems. Then, a Polish version of the scale was formed by competent judges ( 2 psychologists proficiently speaking both languages) by selection of items consistently translated by all translators ( 13 items) and by 2 translators (3 items). This scale underwent back translation to English by 2 psychologists professionally translating to and from both languages. The most consistent items with the original English version were included in the final Polish version of the scale by competent judges. The Cronbach's $\alpha$ of the Polish version for the studied sample $(\mathrm{N}=168)$ was 0.69 for the Work-Family Conflict Scale, 0.63 for Family-Work Conflict Scale, 0.68 for Work-Family Facilitation Scale, and 0.63 for Family-Work Facilitation Scale.

\section{Marital communication}

The Marital Communication Questionnaire [33] was applied to assess marital communication style. The questionnaire consists of 30 items divided into 3 subscales measuring 3 styles of communication. Two scales refer to constructive communication style (Support, Engagement) and one to destructive communication style (Depreciation). Cronbach's $\alpha$ coefficients of these scales were 0.88 $0.93,0.77-0.87$ and $0.86-0.91$, respectively. An example item belonging to the Support Scale was: "I'm interested in my partner's successes and problems," an Engagement Scale example was: "I express care about my partner" and an example item of the Depreciation Scale was: "I criticize my partner." For each item a 5-point frequency-based response scale was used ( $1=$ never, $5=$ always $)$. Higher scores reflected a higher level of a given communication style.

\section{Job satisfaction}

The 20-item Minnesota Job Satisfaction Questionnaire [34] was used to measure job satisfaction. The respondents indicated their degree of satisfaction with different aspects of their job (e.g., pay, chances for development) using a 5-point Likert-type scale ( 1 = very dissatisfied, $5=$ very satisfied). Higher scores reflected greater job satisfaction. The following are example items of different aspects of a job which the respondents rated their degree of satisfaction with, i.e., level of satisfaction with: "Utilization of your abilities," "Supervision-human relations," "Company policies and practices."

There was no Polish adaptation of this technique. The questionnaire was translated into Polish for the purpose of the studies carried out in the Institute of Applied Psychology. First, 3 independent translations of the questionnaire from English to Polish were prepared by 3 psychologists speaking proficiently both languages. Then, the items consistently translated by 3 (15 items) and 2 translators (5 items) were selected for the Polish 
version of the questionnaire by competent judges (2 psychologists proficiently speaking both languages). This version was then translated back to English independently by 2 psychologists professionally translating to and from both languages. The most consistent items with their English versions were included in the final Polish version of the questionnaire by competent judges. Cronbach's $\alpha$ of the questionnaire for this study sample was 0.89 .

\section{Physical health}

The Physical Health Questionnaire (a part of Standard Shiftwork Index [35]) was applied as a measure of health. It contained questions concerning gastrointestinal and cardiovascular problems since shiftwork has been evidenced to be a risk factor for cardiovascular and gastrointestinal diseases [4]. A sample item for the Scale of Cardiovascular Symptoms was: "Do you suffer from shortness of breath when climbing the stairs normally?" and for the Scale of Gastrointestinal Symptoms was: "How often do you have to watch what you eat to avoid stomach upsets?" The respondents indicated how often they experienced symptoms of poorer cardiovascular and gastrointestinal health using 5 response options $(1=$ almost never to $5=$ almost always). Higher scores reflected poorer health.

There was no Polish adaptation of this questionnaire. The forward-back translation of this questionnaire was done for the purpose of this study. Independent translations from English to Polish were done by 3 physicians speaking English proficiently. Then, the competent judges (2 medical doctors speaking proficiently both languages) selected consistently translated items to the Polish version of the questionnaire. Then, their English translations were provided independently by 2 English native speakers, medical doctors working in Poland and proficiently speaking Polish. The items which were the most consistent with their original version were included in the Polish version of the questionnaire by competent judges. Cronbach's $\alpha$ (for this study sample) of the Scale of Cardiovascular Symptoms was 0.87 and of the Scale of Gastrointestinal Symptoms -0.86 .

First, the descriptive statistics of all the variables were computed and then the one-way analyses of variance were performed on the data. The post hoc Tukey's honest significant difference (HSD) test was applied.

\section{RESULTS}

The shift schedule groups differed significantly with regard to work-family facilitation $(\mathrm{F}(3,165)=4.175, \mathrm{p}=0.007)$ (Table 2). Post hoc testing indicated that the workers on the weekly rotating 2-shift system (afternoon and night) experienced significantly less frequent work to family facilitation compared to the other groups $(\mathrm{p}=0.004)$.

Table 2. Scores in the Work-Family Spillover Scale (WFSS) among the transport service shift workers ( $\mathrm{N}=168)$

\begin{tabular}{lcccc}
\hline \multirow{2}{*}{ Work system } & \multicolumn{4}{c}{$\begin{array}{c}\text { WFSS scores } \\
(\mathrm{M} \pm \mathrm{SD})\end{array}$} \\
\cline { 2 - 5 } & $\begin{array}{c}\text { work-family } \\
\text { conflict }\end{array}$ & $\begin{array}{c}\text { family-work } \\
\text { conflict }\end{array}$ & $\begin{array}{c}\text { work-family } \\
\text { facilitation }\end{array}$ & $\begin{array}{c}\text { family-work } \\
\text { facilitation }\end{array}$ \\
\hline Day shifts & $2.48 \pm 0.87$ & $2.35 \pm 0.76$ & $3.19 \pm 0.87$ & $3.27 \pm 0.68^{*}$ \\
Weekly rotating 2-shift & $2.72 \pm 0.70$ & $2.38 \pm 0.58$ & $2.98 \pm 0.70^{*}$ & $3.31 \pm 0.68^{*}$ \\
Weekly rotating 3-shift & $2.64 \pm 0.65$ & $2.36 \pm 0.69$ & $3.32 \pm 0.65$ & $3.56 \pm 0.54$ \\
4 team 3-shift & $2.59 \pm 0.78$ & $2.31 \pm 0.75$ & $3.48 \pm 0.78$ & $3.63 \pm 0.65$ \\
\hline
\end{tabular}

$\mathrm{M}$ - mean; SD - standard deviation.

* Significantly different results, $\mathrm{p}<0.05$. 
Another statistically significant difference between the workers on different shift systems appeared for the Family-Work Facilitation Scale $(\mathrm{F}(3,165)=2.689$, $\mathrm{p}=0.048$ ). The day workers and workers on the weekly rotating 2-shift system (afternoon and night) experienced family-work facilitation less frequently than the other groups under the study. Post hoc testing indicated that the scores of the workers of the 4 team 3-shift system when compared to the scores of the workers of the 2-shifts (afternoon and night) weekly rotating system approached statistical significance $(\mathrm{p}=0.07)$.

There were no statistically significant differences with regard to the Work-Family Conflict Scale $(\mathrm{F}(3,165)=0.569, \mathrm{p}=0.636)$ and Family-Work Conflict Scale $(\mathrm{F}(3,165)=0.134, \mathrm{p}=0.94)$ between the groups of shift workers. The groups tended to have low to average scores in the Work-Family Conflict Scale (scoring 1-5).

There was a significant difference between the shift worker groups with regard to Engagement $(\mathrm{F}(3,165)$ $=2.761, \mathrm{p}=0.044)$ (Table 3$)$. The workers on the 4 team 3 -shift system reported significantly higher scores of Engagement (style of marital communication) than the workers on the 2-shift weekly rotating shift system $(\mathrm{p}=0.026)$.

The groups did not differ significantly with regard to work (job satisfaction, $F(3,165)=0.619, p=0.604$ ) and physical health related variables (cardiovascular symptoms, $\mathrm{F}(3,165)=1.478, \mathrm{p}=0.223$; gastrointestinal symptoms, $\mathrm{F}(3,165)=0.546, \mathrm{p}=0.651)($ Table 4$)$.

Table 3. Scores in the Marital Communication Questionnaire among the transport service shift workers ( $\mathrm{N}=168)$

\begin{tabular}{lccc}
\hline \multirow{2}{*}{ Work system } & \multicolumn{3}{c}{$\begin{array}{c}\text { Marital communication style } \\
(\mathrm{M} \pm \mathrm{SD})\end{array}$} \\
\cline { 2 - 4 } & support & engagement & depreciation \\
\hline Day shift & $4.10 \pm 0.57$ & $3.63 \pm 0.49$ & $1.88 \pm 0.48$ \\
Weekly rotating 2-shift & $3.99 \pm 0.62$ & $3.51 \pm 0.58$ & $1.99 \pm 0.61$ \\
Weekly rotating 3-shift & $4.07 \pm 0.69$ & $3.69 \pm 0.59$ & $1.91 \pm 0.57$ \\
4 team 3-shift & $4.15 \pm 0.73$ & $3.84 \pm 0.60^{*}$ & $1.91 \pm 0.78$ \\
\hline
\end{tabular}

$\mathrm{M}$ - mean; SD - standard deviation.

* Significantly different results, $\mathrm{p}<0.05$.

Table 4. Scores in the Job Satisfaction Questionnaire (JSQ) and the Subjective Health Questionnaire (SHQ) among the transport service shift workers $(\mathrm{N}=168)$

\begin{tabular}{lccc}
\hline \multirow{2}{*}{ Work system } & \multicolumn{3}{c}{$\begin{array}{c}\text { Questionnaires scores } \\
(\mathrm{M} \pm \mathrm{SD})\end{array}$} \\
\cline { 2 - 4 } & work satisfaction (JSQ) & $\begin{array}{c}\text { cardiovascular symptoms } \\
\text { scale (SHQ) }\end{array}$ & $\begin{array}{c}\text { gastrointestinal symptoms } \\
\text { scale (SHQ) }\end{array}$ \\
\hline Day shift & $3.45 \pm 0.52$ & $1.69 \pm 0.71$ & $1.95 \pm 0.55$ \\
Weekly rotating 2-shift & $3.38 \pm 0.51$ & $1.77 \pm 0.65$ & $2.06 \pm 0.69$ \\
Weekly rotating 3-shift & $3.40 \pm 0.44$ & $1.60 \pm 0.60$ & $1.76 \pm 0.65$ \\
4 team 3-shift & $3.49 \pm 0.38$ & $1.76 \pm 0.71$ & $2.01 \pm 0.70$ \\
\hline
\end{tabular}

M - mean; SD - standard deviation. 


\section{DISCUSSION}

This study aimed at comparison of the groups of transport service shift workers on 4 different work schedules with regard to work-family conflict and facilitation, marital communication style, job satisfaction and health. The results showed that the workers on the 4 team 3 -shift system manifested significantly higher levels of work-family facilitation and family-work facilitation than the workers on the weekly rotating 2-shift (afternoon and night) system. Such results lent some support to hypothesis 1(a) regarding potential differences between workers on a weekly rotating 2-shift (afternoon and night) system and those working a 4 team 3-shift system. This is consistent with the research showing less disruption of social life by the 4 team 3-shift systems when compared to the systems with slower rotation [e.g., 24,29]. Relatively short periods of working one kind of a shift in a row (4 days) and a few days off in a row (at least 2) are less disruptive for biological rhythms.

Additionally, they are less disruptive for social cycles since they exclude workers from their families for shorter periods than the weekly rotating 2-shift system. The results suggest that the 4 team 3 -shift system may be more "family friendly" than the other shift systems compared in this study.

The groups of workers in this study did not differ with respect to work-family conflict or to family-work conflict. This is opposite to the results of the other studies comparing work-family and family-work conflict among day workers and shift workers [e.g., 6]. Thus, hypothesis 1(b) was not supported. Moreover, all the groups reported low work-family and family-work conflict. However, characteristics of the participants' work and family situations may explain these results.

First, the participants worked low-level jobs (e.g., diagnostician, electrician, mechanic, whitesmith, painter, upholsterer) and had relatively low levels of educational attainment (trade school). Recent research has demonstrated that work-family conflict was more pronounced among women, among higher-level workers and in higher educational groups [36].
Second, the participants were middle aged men with a relatively long work experience and with their youngest child between 13-17 years of age. The research showed that for younger families with young children work-family conflict is more pronounced than in older families with adolescent children [13]. Finally, these results can be explained in terms of a life- and career-stage perspective developed by Dutch authors [37]. Life stages are proposed to partly determine job demands and job resources as well as family demands and family resources. Thus, the late adulthood stage of the participants in this study may be associated with the experience of low work-family conflict and high work-family facilitation due to the relatively low demands and high resources in work and family domains that are characteristic for this stage of life and working career [e.g., 37].

The workers on the 4 team 3-shift system manifested more constructive (Engaged) marital communication styles than the workers on the 2-shift weekly rotating system. This offers support to hypothesis 3 . This finding is consistent with research showing a moderating effect of constructive and destructive marital communication styles on work-family conflict [16]. It was reasonable to argue that more constructive styles of communication predominated in the groups of workers exhibiting higher levels of family-work and workfamily facilitation than in the group demonstrating lower levels of work-family and family-work facilitation.

Indeed, earlier research has shown negative effects of nonstandard schedules on partnership quality [e.g., 13]. However, more recent research has shown that the effect of nonstandard schedules depends on the schedule parameters. For example, a study by Mills and Täht [18] demonstrated that varying working hours were particularly detrimental for the relationship quality of women who had children at home. Hypothesis 1(a) was not supported because the different work schedules did not appear to have an effect on job satisfaction. All the groups reported a relatively high level of job satisfaction. Similarly, hypothesis 1(b) was not supported. 
The different working time arrangement groups reported rare health complaints. That is, the groups did not differ with regard to cardiovascular and digestive symptoms, which were reported to be common in the shift workers when compared to the day workers [e.g., 4].

Such results might be explained by the "healthy worker effect" [38]. The workers in this study had a relatively long shift work experience. This may reflect a selection process in terms of survivor effects, whereby those less able to tolerate the demands of the workplace leave, while the relatively healthy tolerant individuals stay at work. This, as well as assessment of job satisfaction obtained in this study, is consistent with the findings of research on positive workfamily relationships and its outcomes. Meta-analyses of research findings demonstrated positive correlations between work-family and family-work enrichment with job satisfaction, family satisfaction, and physical and mental health [39]. Results of the research provide an additional reason for the development and application of fast rotating shift systems as less disruptive not only for the shift workers' somatic and mental health.

It is notable that no statistically significant better outcomes for the day workers compared to the shift workers were observed in this study. This could be considered somewhat surprising given that the day workers were treated in the research as a comparison group relative to the shift workers. However, the lack of significant difference between the day and shift workers may be a reflection of work period start time and location of free time in the working week. The day workers in this study started work in the morning at 6 a.m. Such early morning starts have been shown to be stressful as a result of morning shift sleep deficit [40]. Additionally, the 1-2 free days during the workweek provided by the fast rotating shift systems might have better facilitated fulfillment of home care duties when compared to no free days during the work week for day shift system.

This study being based on a convenience sample of a relatively small size and high homogeneity with regard to gender and family life stage does not allow wider generalization of the results. However, it helps to draw clearer conclusions concerning this group of workers.

Overall, the research findings show that there are differences in work-family linkages and their outcomes in relation to workers on different shift systems. The regular, faster rotating 3-shift system appeared to be more family friendly than the regular, slower (weekly) rotating 2-shift (afternoon and night) system. A novel aspect of this study is its concentration on positive and negative work-family and family-work relationships and their outcomes among the workers on different shift schedules. There is a scarcity of studies on a positive relation between work and family both in shiftwork and work-family research areas.

Moreover, there is a shortage of research on the effect of different working time scheduling on work-family relationship. Finding a more constructive marital communication style (engaged style) in the group of participants working the apparently more family friendly shift system (3-shift, 4 team 3-shift system) compared to the group working the weekly rotating afternoon and night shift system is another strong point of the research. The results would merit further examination in longitudinal studies into the extent that antisocial shift schedules may facilitate development of deconstructive marital communication styles.

\section{CONCLUSIONS}

Allocation of working hours within a day and a workweek may have an effect on work and family domains since a higher level of work-family facilitation, and a more constructive style of marital communication were found among the workers of the quicker rotating 3-shift systems when compared to the workers of the slower rotating 2-shift system (afternoon, night). The finding concerning communication style, however, should be treated cautiously because of the cross-sectional character of this study. Therefore, it needs further examination in a longitudinal study. 


\section{REFERENCES}

1. Eurofound. Fifth European Working Conditions Survey. Luxemburg: Publication Office of the European Union; 2012.

2. United States Department of Labor: Bureau of Labor Statistics. Workers on flexible and shift schedules in May 2004. Washington: The Department; 2005.

3. Greenhaus JH, Beutell NJ. Sources of conflict between work and family roles. Acad Manage Rev. 1985;10:76-88.

4. Costa G. Shift work and occupational medicine: An overview. Occup Med. 2003;53:83-8, https://doi.org/10.1093/occmed/kqg045.

5. Härmä M, Kecklund G. Shift work and health - How to proceed? Scand J Work Environ Health. 2010;36(2):81-4, https://doi.org/10.5271/sjweh.2902.

6. Demerouti E, Guert AE, Bakker AB, Eurema M. The impact of shiftwork on work - Home conflict, job attitudes and health. Ergonomics. 2004;47:987-1002, https://doi.org/10.10 80/00140130410001670408.

7. Barnett R, Gareis K. Shift work, parenting behaviors and children's socio-emotional well-being: A within-family study. J Fam Issues. 2007;28:727-48, https://doi.org/ 10.1177/0192513X06298737.

8. Siemiginowska P, Iskra-Golec I, Wątroba J. [Work/family relationship, job satisfaction, satisfaction with life and health among shift and day working nurses]. Ann Univ Paedag Crac Stud Psychol. 2014;8(159):138-52. Polish.

9. Barnes-Farrell JL, Davies-Schrils K, McGonagle A, Walsh B, Di Milia L, Fischer FM, et al. What aspects of shiftwork influence off-shift well-being of healthcare workers? Appl Ergon. 2008;39:589-96, https://doi.org/10.1016/j.apergo.2008.02.019.

10. Grosswald B. Shift work and negative work-to-family spillover. J Sociol Soc Welf. 2003;30(4):31-56.

11. Van Amelsvoort LGPM, Jansen NWH, Swaen GM, van den Brandt PA, Kant I. Direction of shift rotation among three-shift workers in relation to psychological health and work-family conflict. Scand J Work Environ Health. 2004;30: 149-56, https://doi.org/10.5271/sjweh.772.
12. Jansen NWH, Mohren DCL, van Amelsvoort LGPM, Jansen N, Kant I. Changes in working time arrangements over time as a consequence of work-family conflict. Chronobiol Int. 2010;27:1045-61, https://doi.org/10.3109/07420528.2010.489874.

13. Davis KD, Goodman WB, Pirretti AE, Almeida DM. Nonstandard work schedules, perceived family well-being, and daily stressors. J Marriage Fam. 2008;70:991-1003, https:// doi.org/10.1111/j.1741-3737.2008.00541.x.

14. Zalewska A. [Sex and life stage and work-family conflicts, job satisfaction and family satisfaction]. In: Golińska L, Bielawska-Batorowicz LE, editors. [Family and work in crisis conditions]. Łódź: Wydawnictwo Uniwersytetu Łódzkiego; 2008. p. 365-79. Polish.

15. Guzman L. Effects of wives's employment on marital quality. NSFH working paper no. 85. Madison (WI): University of Wisconsin; 2000.

16. Carroll SJ, Hill EJ, Yorgason J, Larson J, Sandberg J. Couple communication as a mediator between work-family conflict and relationship satisfaction. Contemp Fam Ther. 2012;35(3):530-45, https://doi.org/10.1007/s10591-013-9237-7.

17. Presser H. Nonstandard work schedules and marital instability. J Marriage Fam. 2000;64:2-15, https://doi.org/10.1111/ j.1741-3737.2000.00093.x.

18. Mills M, Täht K. Nonstandard work schedules and partnership quality: Quantitative and qualitative findings. J Marriage Fam. 2010;72:860-75, https://doi.org/10.1111/j.1741-3737. 2010.00735.x.

19. Greenhaus JH, Powell GN. When work and family are allies: A theory of work-family enrichment. Acad Manage Rev. 2006;31:72-92, https://doi.org/10.5465/AMR.2006.19379625. 20. Wayne JH. Reducing conceptual confusion: Clarifying the positive side of work and family. In: Crane DR, Hill J, editors. Handbook of families and work: Interdisciplinary perspectives. Lanham (MD): University Press of America; 2009. p. 105-40.

21. Voydanoff P. Social integration, work-family conflict and facilitation, and job and marital quality. J Marriage Fam. 2005;67:666-79, https://doi.org/10.1111/j.1741-3737.2005. 00161.x. 
22. Riley LA, Glass JL. You can't always get what you want: Infant care preferences and use among employed mothers. J Marriage Fam. 2002;64:2-15, https://doi.org/10.1111/ j.1741-3737.2002.00002.x.

23. Barnett R, Gareis K, Brennan R. Wives'shift work schedules and husbands' and wives' well-being in dual earner couples with children: A within couples analysis. J Fam Issues. 2008;32:84-97, https://doi.org/10.1177/0192513X07305346.

24. Knauth P. The design of shift systems. Ergonomics. 1993;36:15-28, https://doi.org/10.1080/00140139308967850.

25. Maume DJ, Sebastian RA. Gender, nonstandard work schedules, and marital quality. J Fam Econ Issues. 2012;33: 477-90, https://doi.org/10.1007/s10834-012-9308-1.

26. Loudoun R. Balancing shift work and life outside work: Do 12-h shifts make a difference? Appl Ergon. 2008;39:572-9, https://doi.org/10.1016/j.apergo.2007.12.004.

27. Fenwick R, Tausig M. Scheduling stress: Family and health outcomes of shift work and schedule control. Am Behav Sci. 2001;44:1179-98, https://doi.org/10.1177/00027640121956719.

28. Smith L. [Shift work stress models]. In: Iskra-Golec I, Costa G, Folkard S, Marek T, Pokorski J, Smith L, editors. [Shift work stress]. Kraków: Universitas; 1998. p. 47-63. Polish.

29. Knauth P, Hornberger S. Changes from weekly backward to quicker forward rotating shift system in the steel industry. Int J Ind Ergon. 1998;21:267-73, https://doi.org/10.1016/ S0169-8141(97)00049-8.

30. Lachowska B. [Interaction of work and family - Perspective of conflict and facilitation (pilot study report)]. In: Golińska L, Dudek B, editors. [Family and work from the perspective of challenges and dangers]. Łódź: Wydawnictwo Uniwersytetu Łódzkiego; 2011. p. 431-44. Polish.

31. Grzywacz JG, Marks NF. Reconceptualizing the work-family interface: An ecological perspective on the correlates of positive and negative spillover between work and family. J Occup Health Psychol. 2000;5:111-26, https://doi.org/ 10.1037/1076-8998.5.1.111.

32. Grzywacz JG, Bass BL. Work, family and mental health: Testing different models of work-family fit. J Marriage Fam. 2003;65(1):248-62, https://doi.org/10.1111/j.1741-3737.2003. 00248.x.

33. Plopa M. [Marital Communication Questionnaire. Handbook]. Warszawa: Vizja Press \& IT; 2008. Polish.

34. Weiss DJ, Davis RV, England GW, Lofquist LH. Manual for the Minnesota Satisfaction Questionnaire. Minneapolis: University of Minnesota; 1967.

35. Barton J, Spelten E, Totterdell P, Smith L, Folkard S, Costa C. The Standard Shiftwork Index: A battery of questionnaires for assessing shiftwork-related problems. Work Stress. 1995;9(1):4-30, https://doi.org/10.1080/02678379508251582.

36. DiRenzo RS, Greenhouse JH, Weer CH. Job level, demands and resources as antecedents of work-family conflict. J Vocat Behav. 2011;78:305-14, https://doi.org/10.1016/j.jvb. 2010.10.002.

37. Demerouti E, Peeters MCW. Work-family interface from a life career stage perspective: The role of demands and resources. Int J Psychol. 2012;47:241-58, https://doi.org/10.108 0/00207594.2012.699055.

38. Knutsson A. Health disorders of shift workers. Occup Med. 2003;53:103-8, https://doi.org/10.1093/occmed/kqg048.

39. Masuda AD, MacNall LA, Nicklin JM. A meta-analytic review of the consequences associated with work-family enrichment. J Bus Psychol. 2010;25:38-95, https://doi.org/ 10.1007/s10869-009-9141-1.

40. Knauth P, Costa G. Psychosocial effects. In: Colquhoun WP, Costa G, Folkard S, editors. Shiftwork. Problems and solutions. Frankfurt: Peter Lang; 1996. p. 89-103.

This work is available in Open Access model and licensed under a Creative Commons Attribution-NonCommercial 3.0 Poland License - http://creativecommons.org/ licenses/by-nc/3.0/pl/deed.en. 